\title{
Guardians and Targets: A Routine Activity Approach to Terrorism in Southeast Asia
}

\author{
Camille Laurence Pauline Bigot \\ Department of Criminology, University of Cambridge, Cambridge, UK \\ Email: c.bigot29@gmail.com
}

How to cite this paper: Bigot, C.L.P. (2017) Guardians and Targets: A Routine Activity Approach to Terrorism in Southeast Asia. Open Journal of Social Sciences, 5, 140-163. https://doi.org/10.4236/jss.2017.512011

Received: November 6, 2017

Accepted: December 18, 2017

Published: December 21, 2017

Copyright $\odot 2017$ by author and Scientific Research Publishing Inc. This work is licensed under the Creative Commons Attribution International License (CC BY 4.0).

http://creativecommons.org/licenses/by/4.0/

\section{c) (i) Open Access}

\begin{abstract}
Since 9/11, terrorism has been an important subject of study within the political and social fields, having often been examined critically. However, empirical frameworks have been lacking within the study of terrorism. This paper aims to counter reductionist views of terrorism and provide a holistic analysis under the arch of a criminological ontological framework. This study tests the relevance of routine activity theory to terrorism, taking the specific case study of terrorism within Southeast Asia. Working with Interpol, terror attacks, and counter-terrorism operations were quantified to mathematically model Routine Activity Theory where I aimed to find predictive terror patterns. Using a time-series analysis of terrorist attacks and counter-terrorism operations, Deterrence Theory, Randomness Theory in targeting and Contagion theory will be tested. A comparative framework will be established between religious attacks and politically related ones. My research aims to disprove any discursive assumptions of terrorism through a quantitative empirical focus. Furthermore, it aims to find patterns within terrorism to learn how to better combat it.
\end{abstract}

\section{Keywords}

Terrorism, Southeast Asia, Criminology, Routine Activity Theory, Counter-Terrorism, Security, Deterrence, Contagion Theory, Randomness Theory

\section{Introduction}

Since $9 / 11$, there has been a wide academic focus onto extremist religious terrorism. This powerful discourse, is, however misleading in defining terrorism as a multi-faceted phenomenon. Duyvesteyn conceptualizes a discursive dichotomy stemming from this publicization of terrorism between new terrorism, embedded 
in a mediatized phenomenon, and old terrorism (2004) [1]. The new perpetrators are seen as transnationally connected and religious fanatics who engage in indiscriminate targeting (2004: p. 443). Drawing onto this discursive focus of the jihad, terrorism has been normalized to the risk of essentialization. "Reductionist narratives of attacks" construct a skewed image of terrorism in the world (Cymer, 2003: p. 28) [2]. This study thus aims to counter reductionist views and provide a holistic analysis of the under-workings of terrorism within a criminological ontological framework and an empirical epistemology.

Based on the record of 73,961 terrorist attacks from 206 attacks over 36 years, La Free et al. attempted to find temporal and geographical patterns in the way terrorism operates (2010) [3]. Drawing on their quantitative study, I aim to pursue a similar study on terrorism in Southeast Asia. Going beyond a simple critical approach, I endeavor to construct a new conceptual framework of terrorism based on quantification and mathematical modeling under the theoretical arch of Routine Activity Theory.

Drawing onto Cohen and Felson's work, motivation to commit a crime is seen as a given within this thesis (1979) [4]. Routine Activity Theory is based on three figures: likely offender, a suitable target and capable guardian (Chamard, 2010: pp. 213-214) [5]. Thus, we aim to look for behavioral patterns using those three figures. The suitable target is examined in the first section by testing randomness theory within the realm of tactics and targeting. The likely offender is studied in the next section via the medium of attacks analysis. Indeed, the contagion hypothesis will be tested under the arch of Dugan \& Lafree's study of plane hijackings (2005) [6]. Finally, the function and influence of capable guardians will be tackled in our final section which aims to assess the effectiveness of deterrence within our dataset.

\section{A Criminological Approach}

\subsection{Guardians \& Targets: Routine Activity Theory}

Within the arch the rational choice theory framework, many criminological theories evolved inspired by a rational conceptualization. This is the case of Routine Activity Theory pioneered by Cohen and Felson in 1979. Inspired by Hawley's work, they desired to conceptualize society as symbiotic of human activities in space and time (1950) [7]. This ecological conception is different to criminological work that focuses on criminal inclination. Indeed, they take the latter as a given and "examine the manner in which the spatiotemporal organization of social activities helps people to translate their criminal inclination into action" (Cohen \& Felson, 1979: p. 589) [4]. They argue that "structural changes in routine activity patterns can influence crime rates by affecting the convergence in space and time of the three minimal elements of direct-contact predatory violations" (ibid). These three elements are "motivated offenders", "suitable targets' and the absence of capable guardians against a violation" (1979: p. 539). A motivated offender is someone with a reason to commit a crime. A suitable 
target is someone likely to be attacked and a capable guardian is "someone who might intervene to stop or bear witness to any offense" (Crawford \& Evans: p. 775) [8]. The time-space element of this activity suggests that the convergence of all the previous elements may be crucial in the prevention of crime. Sherman et al. notes however that it is difficult to make the distinction between a "criminogenic generator" and an "attractive receptor of crime" (1989: p. 46) [9]. Although this distinction has yet to be resolved, the application of Routine Activity Theory to terrorism could be proven extremely useful to the prevention of terror attacks.

Routine Activity has very rarely been applied to violent crime such as terrorism. It has indeed been more used in the analysis of theft or delinquency. For instance, Osgood and Anderson did a study on adolescent delinquency with over 4000 student participants (2004) [10]. They tested the hypothesis that time spent in unstructured and unsupervised environments with peers led to a higher rate of child delinquency. They concluded that unstructured socialization led to higher aggression. Demographic characteristics have indeed been heavily featured within Routine Activity Theory as independent variables leading to an assessment of probabilities. Drawing onto Felson and Cohen's work, Chamard argues that "the organization of daily life in communities affects the amount of crime by changing the amount of criminal opportunity; crime can thus increase or decrease without any alteration in the motivations of offenders" (2010: p. 212) [5]. The value, inertia, access, and visibility of the target of crime are factors in the suitability of the target (p. 213). Furthermore, new elements have been added to Routine Activity Theory by criminologists. Eck and Weisburd introduced the concept of the "place manager" who was responsible for guarding a place where crime could occur (1995) [11].

Therefore, Routine Activity Theory focuses on the geographical and timely distribution of crime. Chamard concludes that "the significance of crime pattern theory is clear if one focuses on how settings create opportunities for crime" (p. 218). With criminological inclination taken as a given, the field of terror studies through the lens of Activity Routine Theory becomes simpler. Indeed, as mentioned previously, the major dilemmas explored within terrorism have been the causes of terrorism. The focus is therefore drawn on the act, rather than an ontological exploration. Therefore, I believe it is an innovative concept to test this theoretical framework to terrorism.

This paper aims to study specific terror events occurring in space and time, involving specific people and/or objects. The concept of Routine Activity Theory is not new but it has very rarely been applied to terrorism, as well as draws in elements often overlooked by criminologists (Cohen \& Felson 1979: p. 591). The interdependence between terrorist and targets may be fully explored using this theoretical framework. The situational theory has been applied by Weenink to terrorism with the aim to prevent attacks. He concludes that environment affects radicalization (2015) [12]. Engaging in the complex study of terrorism, however, 
means that the application of Routine Activity Theory has some limits. Indeed, building an empirical study on terrorism is challenging due to the difficult access to the data. It is hard to access interviews of terrorists and thus, pinpointing individual motivations. Therefore, this study plans to explore targeting and deterrence more than the decision-making and motivations related to terrorists. To apply Routine Activity Theory, our focus will not be individualistic like past criminological studies. Indeed, terror attacks will be the primary variable analyzed.

There are three actors to the theory: capable offenders, guardians, and suitable targets. Within terrorism, the capable offenders are the terrorists. In this case, I will not focus on the capability of offenders and their radicalization. This thesis assumes the capability of offenders through their affiliation with a terror group, but rather will test the influences of successful attacks on other attacks. Although guardians may be ordinary citizens (Cohen \& Felson, 1979: p. 590), this thesis will focus on the police and the military as the epitome of guardianship. I will indeed test out the theory of deterrence to see the effects of the presence or absence of guardianship on attacks. With the capable offender taken as a given (the terrorist), the guardians and suitable targets will be studied. The guardians are represented by counter-terrorism forces, and the suitable targets are individuals targeted by terror attacks.

\subsection{A Quantitative Methodology}

To collect terror data, I worked in collaboration with Interpol. The previous summer I had undertaken a two months internship at Interpol in their Singapore bureau. I assisted Mr. William Lippert, an intelligence criminal analyst, in the elaboration of the 2016 terror report. Every other year, Interpol publishes regional terror assessments based on the study of a 20-month-period. The 2016 terror report provided an updated view of the 2014 Fusion Taskforce Project Pacific [13].

Interpol is an international organization focused on security and policing. The organization aims to share security-related information. Counter-terrorism strategies are part of Interpol's agenda. With the inauguration of their new headquarters in Singapore, Southeast Asia has also become a focus for the organization. The report's purpose was to raise awareness of the extent to which terror groups are increasingly transnational, to identify intelligence and information gaps that inhibit law enforcement's full comprehension of the terror threat in the Southeast Asia region, to identify the threat of Southeast Asian citizens or residents pose a terror threat to other parts of the world, and to identify potential measures that countries can take to prevent and reduce the threat of terrorism in Southeast Asia.

Interpol makes use of the Jane's IHS Terrorism and Insurgency Centre (JTIC) database which provides detailed statistical analysis of terror incidents in Southeast Asia. The JTIC database is a comprehensive event-based database of incidents 
related to terrorism, insurgency, separatist, political violence, extremism, and other related activities. The database contains a total of almost 200,000 events worldwide from December 2008 to present, with incidents added daily. There are over 8000 of those which involve Southeast Asia.

A total of 1414 terror events have been recorded between January 2014 and July 2015 in Thailand, Myanmar, Malaysia, Indonesia and the Philippines. Vietnam, Laos, Brunei, and Singapore were also included in my regional focus, but the absence or lack of substantial data meant they had been discounted for their statistical insignificance. Indeed, Singapore only holds one terrorism-related arrest between 2014 and 2015. Those events are categorized as either Counter-Terrorism Operations (CT Operations) or Terror Attacks. I plan to go beyond the Interpol report with the use of advanced quantitative methods and criminological theories. Furthermore, academic research about Southeast Asia and terrorism has often been very descriptive. I hope to surpass the descriptive, in order to build a comprehensive and holistic analytical framework.

Previous research on terrorism in Southeast Asia lacks reliable sources (Hamilton-Hart 2005: 308) [14]. With Interpol, the reliability of sources can be assured and will elevate the "raw skepticism about the reliability of information" (2005: p. 309). Indeed, researchers have a role to play in the way terrorism is understood. Hamilton-Hart criticizes the distorted global vision of terrorism with the focus on radical Islamism when terrorism should be examined in local contexts (2005: pp. 320-321). Therefore, a regional focus is important.

Smith states that there is growing "connectivity between local and global movements giving the example of the link between Jemaah Islamiyah (JI) and Al-Qaida" (2010: p. 3) [15]. Cheong and Laundry further criticize this mediatized vision of terrorism that has essentialized terrorism (2012) [16]. They encourage alternative critical discourses to avoid the normalization of transmediated reality constructions. Indeed, discourses are important in the way I construct concepts. Meaning is constructed by discourses of events which leads to "widespread social understandings" of terrorism (Hodges, 2011: p. 5) [17]. The first aim of our study is therefore to portray an accurate representation of terrorism in Southeast Asia and to break any essentialist assumption.

Terrorism has often only been equated to Islamism in media discourses, meaning that terrorism has been reduced to extremist religious terrorism. Within this study, bringing the scope of political terrorism will dismantle those generalizations. Furthermore, Al-Qaida no longer plays a role in Southeast Asia after its dislocation after the killing of Osama bin Laden. The Islamic State, however, is the new leading Islamic organization. Therefore, this study aims to provide an updated analysis of religious terrorism in Southeast Asia. Furthermore, this study aims to assess how countries in Southeast Asia deal with terrorism. Smith associates effective government to effective counter-terrorism (2010). He gives the example of the failure of the Philippines dealing with grievances in the Mindanao region and Thailand failing to recognize Malay-Muslim militancy as poor governance (2010: p. 4). More information on how terrorism operates 
would, however, be useful to provide more effective counter-terrorism in the region. Thus, this study aims to provide a mathematical modeling to terrorism to have a better understanding of the underlying operational structures of terrorism.

The main framework used will be Routine Activity Theory. Can Routine Activity Theory be applied to terrorism? Does the absence of guardians influence the level of attacks? Can deterrence theory be applied to terrorism? Is random targeting applicable? Can contagion theory be applied to this regional focus? Are there relevant patterns within terrorism in Southeast Asia? We thus aim to answer all these questions within our study.

\section{Targets \& Tactics}

In this section, I will be examining targets and tactics related to terror attacks using Routine Activity Theory. I aim to find recurring patterns to be able to see a routine emerging within terror attacks. In the first part of this section, I will be testing randomness theory. Then, I will be comparing political terrorism and religious terrorism to establish similarities and differences in terror strategies. Finally, I will take a deeper look at Routine Activity by modeling targeted objects and sectors in time to build a holistic longitudinal framework.

\subsection{Randomness Theory or Routine Activity Theory?}

Successful terrorist attacks are based on the existence of motivated offenders and of unprotected victims (Hesch \& Pedahzur, 2004: p. 486) [18]. In this section, I would like to test the randomness hypothesis related to terror attacks. Random theory attests that because of the maximization of casualties, targeting is randomized and thus proportionally distributed in terms of target sectors and objects. Contrary to randomness theory, Routine Activity Theory would hypothesize skewed data where there is a higher probability of terror attacks happening in one sector, targeting certain individuals. Hesch and Pedahzur test randomness theory related to terror victimization (2004). Their study is demographically based where they measure victim's backgrounds (2004: p. 489). They argue that most victims were unmarried men with non-settlers having a higher chance of being targeted (p. 492). However, regarding suicide terror attacks, women are more likely to be killed due to the heavy targeting of commercial areas (p. 494). Randomness theory is however refuted due to the high rate of terror attacks in urban environment and vulnerability based on gender and marital status, as well as proximity to populated public areas (p. 496).

With the terror attacks dataset, I will examine the targeted people, targeted sectors and assess the difference between urban/rural environments. I am unfortunately unable to assess victimization due to the unavailability of the information, but randomness theory may still be tested through tactics and targets. Hesch and Pedahzur judge their study limited regionally with a focus on the Israeli-Palestinian conflict, thus a focus on Southeast Asia may provide new information and reconceptualization. 


\subsection{Targeting}

I have compiled all the attacks from all the countries studied in our analysis. I have regrouped some tactical categories here to reduce the number of categories. For instance, the categories of seize and ambush were regrouped together, as well as shootings and stabbings under assassinations.

An initial observation brings out the lack of suicide bombings. Indeed, suicide terrorism has been heavily studied within the rational choice framework with the destruction of the Iraqi Embassy in Beirut in 1981 seen as the first suicide bombing (Atran, 2003: p. 1535) [19]. Indeed, "suicide bombers are expendable assets whose losses generate more assets by expanding public support and pools of potential recruit" (p. 1538). Reaching targets is however essential, usually in populated public spaces. With the absence of suicide terrorism, it is therefore interesting to see new terror conceptions emerge.

With a large amount of political terrorism seen in Myanmar and Thailand, it is without surprise that Direct Fire Infantry is the most used tactic. Overall, with the descriptive of the frequencies, it seems that randomness is disproved as the data is always skewed towards one category. This correlates with the finding that domestic military clashes are the most common targeted sector, meaning an open field clash between militants and military is the most common terror attacks seen in Southeast Asia.

With $60.5 \%$ of attacks happening in rural areas, it appears that the Southeast Asian countryside is more vulnerable to terrorist activity. I conjecture that this could be explained by the higher presence of policing in cities. This is attested by our data with $56 \%$ of CT Operations happening in urban areas. It, however, contradicts Hesch and Pedahzur's theory on terrorism as an urban phenomenon (2004: p. 486).

An interesting result is the fact that despite the previous target sector and tactic findings, the highest percentage of targeted people are civilians. This could be explained by civilian casualties during direct fire infantries by militants such as when a man and his son were killed when suspected southern separatist militants opened fire on their vehicle in the village of Ban Plaina in Rueso district of Thailand on June $9^{\text {th }}, 2014$ (the Bangkok Post, 2014). Furthermore, the prevalence of civilian targeting can further be explained by religious terrorism targeting prevalently civilians. This theory will be later developed and tested in this section.

With civilians representing $46.1 \%$ of the targeted people by terror attacks, soldiers are close behind with $36.7 \%$. Examining only targeted civilians and military personnel, I ran a chi-square test to test for significance in distribution. With quite low significance $(0.086)$, the test, however, reveals an equal probability of soldiers and civilians getting targeted by terrorist attacks.

Civilians are more likely to be killed in vehicles (12.6\%) and in commercial zones which includes shopping centers and markets (10.5\%). When examining data only of civilians being attacks in vehicles and commercial areas, the 
chi-square test reveals moderate significance (0.345), meaning civilians have an equal probability of being killed in vehicles and within commercial spaces. This may be useful for counter-terror forces for the monitoring of shopping centers and markets. Both target sectors, however, have a different appeal where vehicles relate to more individual targeting, whereas big commerce areas seem to indicate a will for mass casualty. $61.6 \%$ of civilians are killed in the rural area. Correlating urban and rural data related to terror attacks on civilians, the two appear closely correlated ( $r=1.038$ ). Indeed, there is an equal probability for a civilian to die in a rural environment and in an urban environment (significance 0.595). On the other hand, $86.6 \%$ of attacks on soldiers are direct military clashes. This does not seem surprising due to the military apparel of soldiers. $62.4 \%$ of terror attacks on soldiers are in rural areas. The chi-square test indicates no equal probability however with urban environments.

\subsection{Political Terrorism}

In order to establish a comparative framework between religious and political terrorism, I have separated our dataset based on types of terrorism. With political terrorism often aiming for regime changes or having separatist agendas, I want to test the hypothesis that political terrorism aims to target the government to make a statement.

The random theory appears disproved when examining large-scale results. Indeed, $60.6 \%$ of attacks were perpetrated as direct fire infantries. This may be explained as that political terror groups are often army factions of political sub-groups and parties. This is the case for instance of the New People's Army as a faction of the Philippines's communist party. These appear to be mostly happening in rural areas, explained by the open-field spaces that make it easier for military confrontations.

Although there seems to be a similar number of hoaxes, assassinations, fires, assaults, and ambushes, there was no significance detected analyzing those tactics exclusively. However, I also ran a test on hacking, hit and runs, landmines, narcotics, riots, robbery, rocket attacks and threat within the political terrorism data set, and they proved to hold an equal probability of existence (significance 0.608). Therefore, the tactical data seems to be skewed in favor of Direct Fire Infantry, but some similarities in probabilities of other tactics to be used are seen within political terrorism.

With Direct Fire Infantry as the main tactic, the target sector and people appear to be perfectly correlated within political terror attacks. Indeed, the most common target sectors are open-fields domestic military clashes $(49.2 \%)$ and the most targeted people are soldiers (49.85\%).

The null hypothesis for equal probabilities is rejected within the target sectors which appear completely unevenly spread out. Discounting civilians and soldiers, the randomness theory regarding targeting is however seen at a weak level with Government Member, Identity Groups and Police Forces (significance 0.109).

Therefore, I can argue that the findings are a little different than expected. 
Government members are not to the most targeted people, nor are government buildings. However, the military in a way is representative of the government. Indeed, it's the defensive organization of a state. Therefore, with the high prevalence of faction armies, it seems logical that the most targeted group in Southeast Asia are soldiers. The political statement against the government is still there, except it not targeted directly at politicians and statesmen.

\subsection{Religious Terrorism}

There is a strong normative academic focus within terror studies that Islamic terrorism targets mostly civilians. Ganor defines terrorism as "the intentional use of, or threat to use, violence against civilians or against civilian targets, in order to attain political aims" (2002) [20]. He emphasizes the focus of civilian targeting by stating that the brutality against the innocent is what produces fear. Therefore, I would like to test this hypothesis with our religious terror attacks data. Furthermore, literature has also focused on the emphasis of a mass casualty of religious terrorism. Jackson says that the purpose of terrorist violence is to intimidate and terrify (2009) [21]. Thus, with civilians as the main targets, it seems the most likely sector would be busy civilian areas. Overall, the main theory to be tested within religious terrorism is the randomness one as mass casualty would imply random targeting. Does religious terrorism target randomly?

Not unlike political terrorism, the most used tactic is Direct Fire Infantry. This might be surprising for the fact that the media has often focused on explosives as a religious terror tactic. However, this can be explained looking closer at the data with religious groups also having armed factions. For instance, on the $15^{\text {th }}$ of July 2015, military clashes left suspected ASG sub-leader dead in the Philippines. Furthermore, groups like BIFF having broken away from the MILF political faction is recognized as an armed militant organization with Islamic beliefs urging for an Islamic state. Therefore, Southeast Asia brings a new conception of religious terrorism. Indeed, with the focus on Al-Qaida, a decentralized terror organization, and foreign fighters of Islamic States, the media has often portrayed religious terrorism adopting no military based operational strategies. Ganor indeed differentiates terrorism and guerrilla warfare through the mean of targeting where terror organizations target the civilian population whereas guerrilla warfare factions target soldiers (2002). This is however not the case here with $48.8 \%$ of people targeted by religious terror attacks being soldiers. Therefore, this study provides a reconceptualization of terrorism where even within religious terrorism, the military seems to be the prevalent target. With the Islamic State mostly operating in Syria and Iraq, one could conjecture that probably the same pattern can be seen in that region with the Iraqi forces often fighting the Islamic Rebels. Thus, there has been a normative misconception within the field of terrorism when it comes to targeting that differs from the reality of sub-state terror targeting.

There is, however, an even distribution between the use of kidnappings, 
explosives, and assassinations (significance 0.262) which perhaps appeal to the more normative conceptualization of religious terrorism. Although Randomness Theory does not seem to be proven on the grand scale of the data, putting direct infantry aside, it still seems there is an equal probability of attacks revolving around kidnappings, explosives, and assassinations (including shootings and stabbings). The least used tactics are threats, fires, and ambushes where significance cannot be tested due to the small sample of the data using those tactics.

Similar to political terrorism, domestic military clashes appear to be the most common tactic. Overall, the target sectors are not evenly distributed, thus rejecting our initial based hypothesis conjecturing mass casualty on civilian-based sector within a randomized targeting framework.

Civilians have a higher probability to get targeted than with political terrorism, but soldiers are still the most targeted individuals which appear as no surprise following the previous tactical and targeting results. With a low significance index of 0.178 , civilians and soldiers have a low equal probability of being targeted. There is an even distribution of targeting within government members, identity groups, policemen and religious members (significance 0.181). A surprising result is that $52 \%$ of attacks occur in rural areas. This is surprising as the often-high density of populations are found within cities where thus mass casualties within a small radius are more likely than in a rural area where population tends to be spread out.

Interesting results were found when examining only civilian targets. Once again, over half of the attacks occurred in rural areas. However, there was a high significance of 0.546 between urban and rural areas, which means civilians are as likely to be targeted in rural areas as they are in urban areas. The tactic most used targeting civilians are kidnappings. For example, on the $1^{\text {st }}$ of May 2015, ASG militants kidnapped a telecommunications worker in the Philippines. Finally, the random hypothesis is proven within target sectors. Indeed, all sectors appear to have an equal probability of being targeted (0.192 significance). This draws back to our initial hypothesis of religious terror group favoring random targeting. However, there is a limitation as $36.2 \%$ of the data is unknown within religious terrorism.

Therefore, it seems random theory can only be proven in the specific case of civilians being targeted, where the sectors of targets appear random. This could be explained by the mass casualty strategy. However, overall the data appears to be reconceptualizing discursive knowledge of terrorism. Moreover, Held states that there is a misconception often within the definitional discourse of terrorism about the killing of the innocent when she states that terrorism has targeted military entities (2004: p. 60) [22]. This is seen within political and religious terrorist attacks.

\subsection{Routine Activity in Time}

Overall, it seems our data not only contradicts Hesch and Pedahzur's findings 
and previous mediatized beliefs about terrorism but also disproves randomness theory. To that effect, testing Routine Activity theory in time allows an assessment of its application going beyond the skewness of the data.

In 2014, there seem to be regular peaks within 3 months periods (Figure 1). This is however not the case in 2015 where the use of direct fire infantry is more linear. The growths of direct fire infantry, however, differ throughout the year. Between January and February 2014, there is a $137.5 \%$ increase in the use of direct fire infantry within terrorism attacks. However, between August and September, there is only a $12 \%$ increase in its usage. Furthermore, the correlation in time is weakly significant with an overall slight negative correlation $(r=0.420)$. This means that the use of direct fire infantry has a tendency to decline over time. I can conclude that Routine Activity Theory is mildly proven in this case, where only a similar evolutive pattern is seen in 2014, with different increases and decreases in tactic usage.

Establishing a comparative framework between civilians and soldiers, I observe a similar evolutive pattern with Figure 1 (Figure 2). Consecutive periods of three months indicate a peak with an increase followed by a decrease for both Civilians and Soldiers. Peaks are however not comparable with different increases seen throughout. This is especially the case for civilian targeting. Before the sudden increase in January 2015, the increases for soldiers are quite similar with increase ratios ranging from 1.2 to 1.7. Overall, civilian killing is greater in 2014, but there is a big change in 2015 with soldiers being killed more than civilians. When correlating both functions, no significance is detected with a Pearson Correlation Test.

With military clashes being the most common attacks, it is more interesting to study a physical sector. One of the significant sector attacks are vehicles with 110 attacks being recorded on vehicles. A different pattern is seen here with a more significant spread of attacks in the period studied (Figure 3 ). With a chi-square test, an equal probability is found between months with a high significance of 0.908. This means that randomness theory can be positively tested examining vehicle attacks. This further means that there is an equal probability of getting an

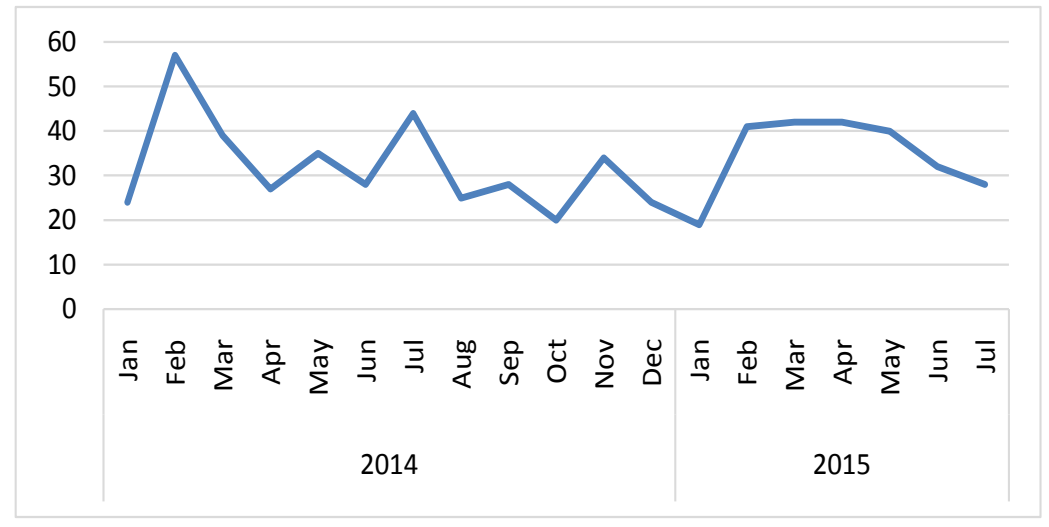

Figure 1. Evolution of the use of direct fire infantry. 


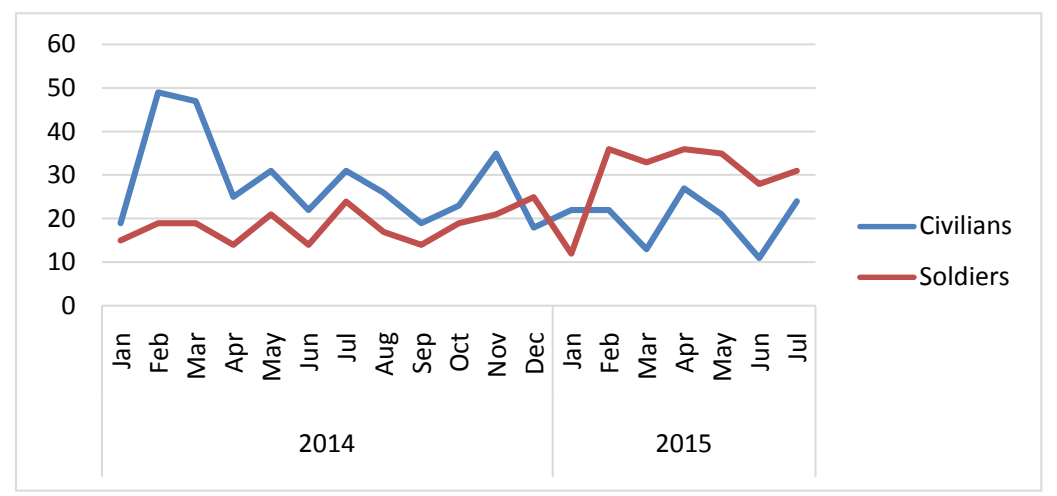

Figure 2. Comparative graph of attacks on civilians and soldiers.

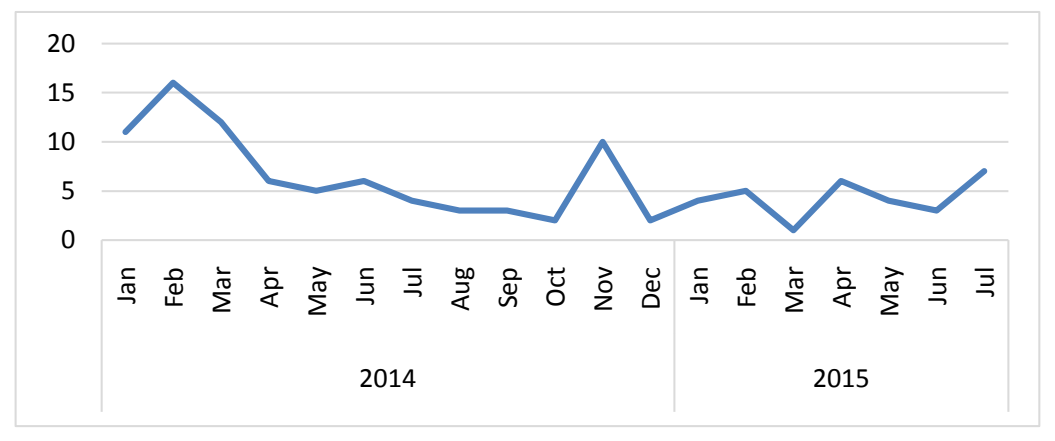

Figure 3. Evolution of attacks on vehicles.

attack in a vehicle throughout 2014 and 2015. That said, the highest record of attacks on vehicles was in February 2014.

Therefore, randomness theory has been overall disproved when it comes to terror patterns in Southeast Asia. Our data suggests routinized targeting with Direct Fire Infantry as the main tactic. Blurring Ganor's differentiation between guerrilla warfare factions targeting the military and terrorists targeting civilians, it appears that there is a heavy confrontation between state militaries and terror organization. This is the case for both religious and political terrorism. Civilians remain the main casualty with an equal probability of death with soldiers. With a clear image of targeting, I aim to push Routine Activity even further in its application to attacks. In the next section, I thus aim to examine contagion in time and space to see if there is an influential pattern within attacks.

\section{Offenders \& Contagion}

Capable offenders plan and undertake terror attacks. In this section, I will be testing contagion effect regarding terror attacks in Southeast Asia. Contagion will be examined in time and space, first regionally and then locally. I aim to see if there are behavioral patterns of attacks based on previous occurrences of attacks.

\subsection{Contagion Theory}

This section will draw on Dugan and Lafree's rational study of plane hijacking 
(2005) [6]. They tested contagion theory in time observing hijackings by studying the evolutive pattern of hijackings after successful and unsuccessful hijackings. They aim to see if the decrease in attacks is due to the belief of lesser success; and if there is, on the other hand, an increase in attacks after successful attacks (2005: pp. 1038-1039). They conclude that "contagion seems to operate only through a rapid occurrence of successful hijackings". However, "counter-hijacking policies have no effects on terrorism-related hijackings" and an increase in punishment and lesser successful attacks only influence non-terrorist events (p. 1056).

I wish to study contagion in both time and space. I aim to establish if an increase in attacks in a region has an effect in a later time in a bordering region. Contagion can thus be modeled through a correlation between increases in attacks between $\mathrm{t}$ and $t+1$ between two regions. Therefore, with a series of attacks in region $A\left(A_{t}\right)$ and a series of attacks in region $B\left(B_{T}\right)$ a perfect contagion model is as follows:

$$
A_{t+1}-A_{t} \approx B_{T+2}-B_{T+1}
$$

Z-scores allow for linear data to be standardized and thus will be used for this section. This means that all data is reduced to a ]-3; 3[ scale which allows for a direct comparison of two series of different values. It thus facilitates the interpretation of the evolution of both data sets of attacks. Z-scores $Z_{x}$ are calculated with the mean $(\bar{x})$ and the standard deviation $\left(S_{x}\right)$ of the series.

$$
Z_{X}=\frac{X_{i}-\bar{X}}{S_{X}}
$$

\subsection{Regional Contagion}

In order to test contagion theory at a regional level, I aim to model the evolution of attacks level in three countries that share a border. These are Myanmar, Thailand, and Malaysia. Z-scores are used to establish a comparative framework regarding the evolution of attacks. In order to test contagion, a rise in an attack in $t$ for one country should lead to a rise of attack in $t+1$ in another.

The evolution of attacks between Thailand and Myanmar appear overall positively correlated (Figure 4). Arguably the only seeming occurrence of contagion is between April 2014 and June 2014 where a peak in Myanmar follows a peak in Thailand. Indeed, attacks doubled in Myanmar between April and May followed by attacks in Thailand having a $28 \%$ rise. The two peaks are thus not proportional, leading me the question their influential significance. The data from Malaysia is uneven and scattered compared to Thailand. No occurrences of clear contagion can be seen between these two countries.

The lack of contagion between Myanmar and Thailand can be explained by the high level of political terror events in both countries. Indeed, political groups are localized and thus often unrelated to each other. The extremely low level of attacks in Malaysia compared to the similar level of attacks in Myanmar and Thailand skews this comparative framework. Moreover, the further lack of 


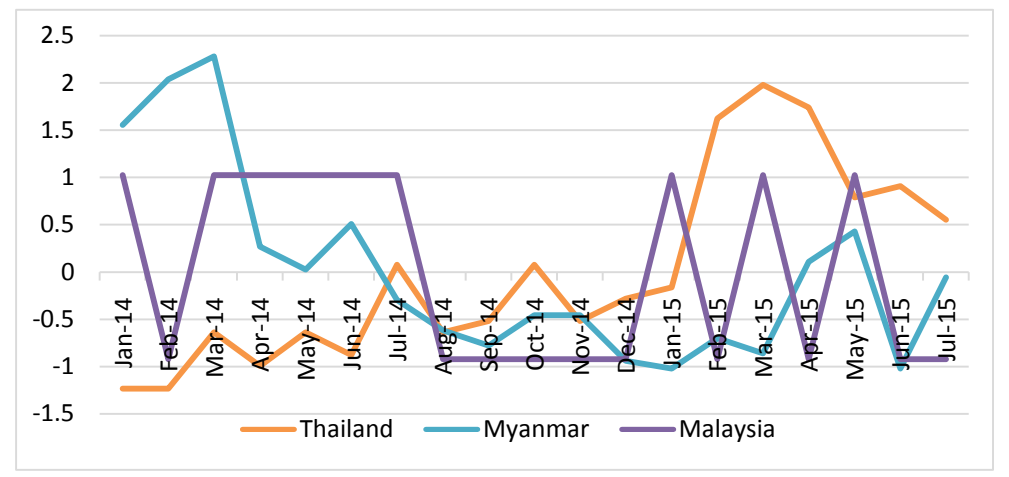

Figure 4. Evolution of attacks in Northern Southeast Asia.

correlation between Thailand and Malaysia can be explained by the prevalence of religious terrorism in Malaysia compared to the significant political terrorism in Thailand.

\subsection{Local Contagion}

With the lack of connections between terror events in countries, it is therefore necessary to examine contagion at a more localized level. The two countries with the highest number of terror events are the Philippines and Myanmar. Within Myanmar, the states of Kashin and Shan have the highest numbers of attacks. To test the contagion effect, I have modeled the evolution of terror attacks in both states with standardized data.

Only one clear instance of contagion is seen with a peak of attacks in Kashin correlated in $t+1$ with a rise of attacks in the Shan state (Figure 5). This is between December 2014 and February 2015 where both in Kashin and the Shan states attacks are multiplied by 8 . It is, therefore, a perfectly proportional rise which appears significant due to the consistency in attacks observed previously in both states. Thus, one could conjecture that there is evidence of contagion between the states of Kashin and Shan with Kashin leading the contagion. This could be explained with the politically motivated groups such as the New People's Army has a similar level of activity in both states. A study of a longer time period might allow for a more comprehensive modeling of contagion.

The Philippines regroups many regions and is a varied country in terms of terror attacks with religious and political terrorism observed. Most of the attacks are located in the South. This study thus aims to examine the correlation between the Caragaregion the Davao region and the Soccskaragen region with Maguindanao. I have associated Maguindanao to the last regional focus to have a similar level of attacks in all three regions.

Between Caraga and Davao a general positive correlation is seen throughout the time periods (Figure 6). Indeed, the peaks in attacks correlate perfectly throughout time meaning that terrorism evolves exactly in the same way. Only one instance of delayed peaks between the two functions can be seen between October and November 2014. However, this is negligible due to the general 


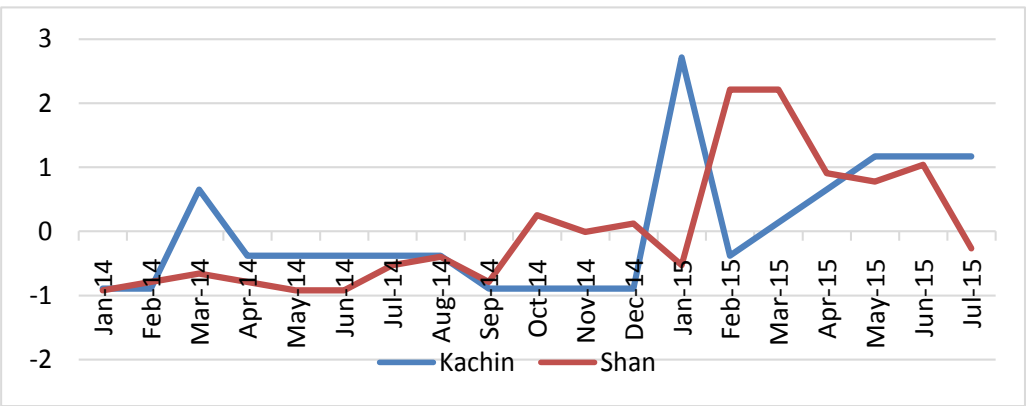

Figure 5. Evolution of attacks in the states of Kachin and Shan.

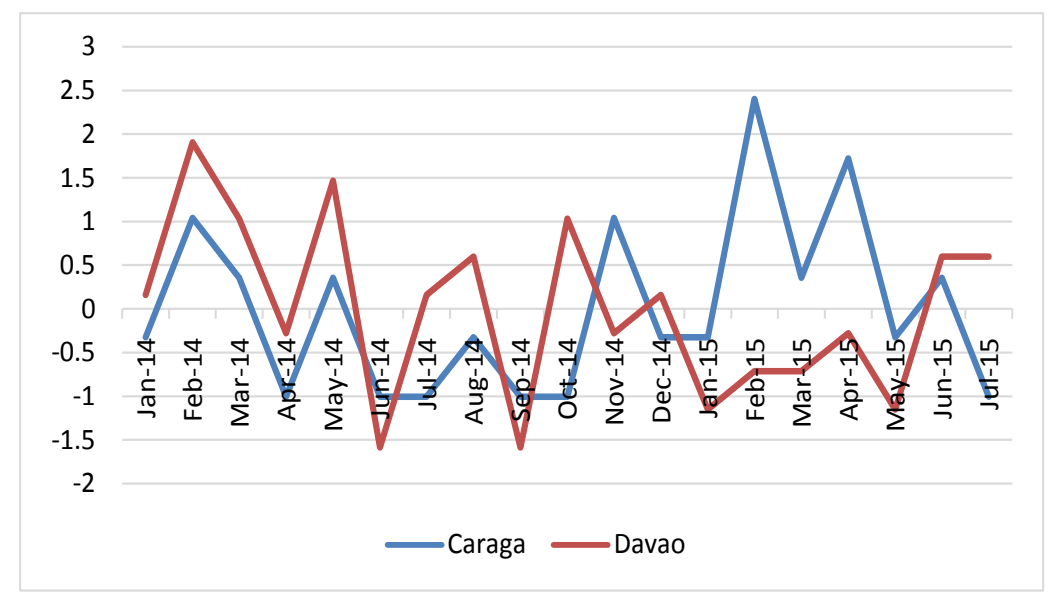

Figure 6. Evolution of attacks in Caraga \& Davao.

similar evolution between Davao and Caraga. This means that contagion is not observed between the two regions. However, the same group is perhaps coordinating the same attacks in both regions.

Different fluctuations are seen in the second graph comparing Soccksargen \& Maguindanao with Davao (Figure 7). From April 2014 to February 2015 there is a contagion effect observed. Indeed, as an attack in Davao rise in a time t, the attacks in Soccksargen \& Maguindanao grow similarly in $t+1$. Four peaks in Davao are observed to be influential in the regions of Soccksargen \& Maguindanao. Averaging the four peaks, for an increase factor of 16.25 in Davao, the level of attacks in the regions Soccksargen \& Maguindanao are multiplied by a factor of 11.33. Therefore, the growths are similar, meaning there is indeed a contagion effect observed between the two regions.

Mathematical modeling of contagion indicates that contagion theory is only seen at a localized level. No contagion effect can be observed at a regional level in Southeast Asia. This can be explained by the high prevalence of political terrorism with often state-focused goals. This means that the links between organizations are weak. Only within the same country, that a behavioral pattern of contagion can be seen in some regions. After seeing the effects of attacks on attacks, I aim to correlate CT operations with attacks. In the next section, I will thus be testing deterrence theory based on guardianship. 


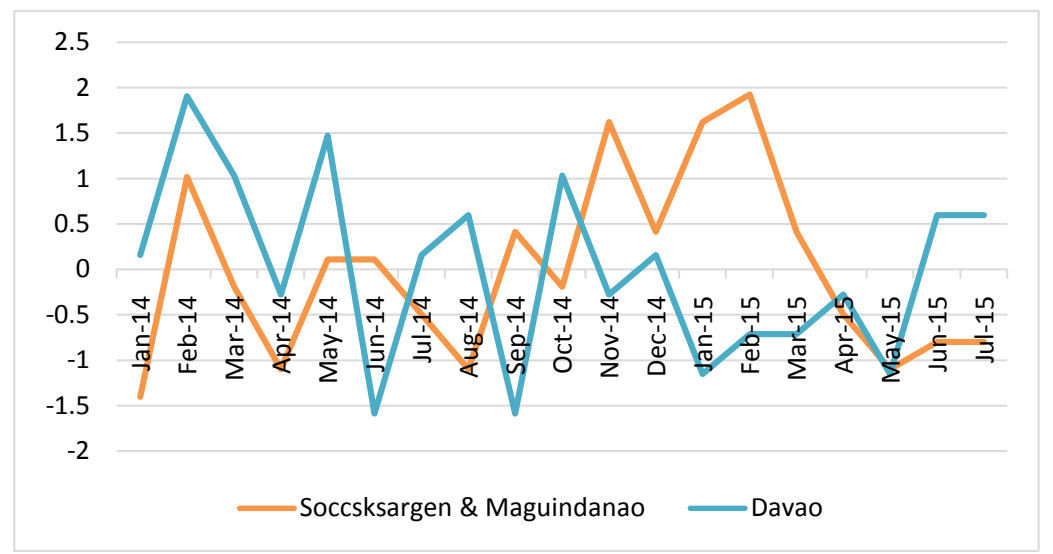

Figure 7. Evolution of attacks in Soccsksargen \& Davao.

\section{Guardians \& Deterrence}

In this last section, I will examine the figure of the Capable Guardian. A correlation will be established between CT Operations and Attacks to test deterrence theory.

\subsection{Terrorism and Deterrence}

Deterrence in the context of the War on Terrorism has been heavy featuring in Criminology. Almog compares cumulative deterrence with the classical deterrence model (2004) [23]. The former is aimed at prevention through nuclear deterrence. The latter is an operational progressive approach with a focus on soft power rather than the hard power approach of classic deterrence (2004: p. 9). Almog concludes that the use of classical deterrence regarding the war on terror was a mistake, which is a "war in need of a cumulative strategy" with intelligence as the main tenant (15). Frey and Luechinger also look for an alternative to classic deterrence. They argue that heavy sanctions and policing, as well as the use of military forces, may not be as effective as a benevolence system (2007: p. 238) [24]. Within a rational choice framework, they aim to raise the "perceived cost of terrorism" in order to reduce terrorism (p. 239). If the scope of opportunities outside of terrorism grows, then radicalization is less likely. They conclude on mixed counter-terrorism methods combining positive sum techniques with classic deterrence, to raise opportunity costs and reducing the cost of the non-violent activity (p. 247).

Therefore, with the available data concentrated on CT Operations and attacks, a comparative framework may be built around the two variables. Deterrence within Routine Activity Theory has been defined in guardianship. Thus, more guardianship deters crime. Reynald expands on Cohen and Felson's work by offering alternative views of guardianship (2011) [25]. Indeed, guardianship has been defined by them as "any spatiotemporally specific supervision of people or property by other people which may prevent criminal violations from occurring" (1979) [4]. 
With terrorism aiming at mass casualty, the concept of semi-formal guardianship does not apply to our case study. Therefore, guardians will only be considered in the formal sense, meaning military, intelligence or police forces. In this case, they are quantified within the CT Operations variable. Deterrence will be defined in as a "threat or action designed to increase adversary's perceived costs of engaging in a particular behavior" where the actions are the CT Operations and the behavior is undertaking terror attacks (Traher \& Zagarcheva, 2005: p. 90) [26]. Dugan \& Lafree state that 'the rational choice perspective predicts that the frequency of aerial hijackings will decrease if the probability of success is decreased, the perceived benefits are reduced, and the perceived costs are increased' (2005: p. 1034) [6]. This also applies to terrorism, where it is assumed that an increase in CT operations will reduce the perceived benefits of terrorism.

\subsection{Modelling Deterrence}

One of the tenants of Routine Activity Theory is the figure of capable guardian figure (Cohen \& Felson, 1979: p. 589). Moreover, the absence of capable guardian factors in criminal behavior. Within that mindset, deterrence theory goes beyond the absence of guardianship. Indeed, it assumes a correlation between guardians and criminals, also known as the "motivated offenders" (ibid). Deterrence works within a variable of time. It assumes within a value $t$ where criminal activity grows, then in $t+1$ policing will also rise. Furthermore, in $t+2$ the criminal activity should decrease proportionally or so as a result of the increase of policing activity.

I have modeled thus deterrence in the following pattern with $\mathrm{x}$ as policing event and y as criminal activity event (Figure 8).

This model can be easily critiqued however due to its perfect correlation. Indeed, often attacks do not equate perfectly instances of policing. Therefore, to model deterrence, a general correlation must be seen when policing grows over time, attacks drop.

\subsection{Testing Deterrence in Southeast Asia}

To test out deterrence I aim to cross-correlate two times series. The first time-series will be the evolution of CT Operations in time between January 2014 and July 2015. The second time-series is of the attacks in the same period of time. Our data now encompasses the entirety of the region with the combination of attacks and operations in Indonesia, Malaysia, Thailand, Myanmar and the Philippines. With many similarities observed, I thus aim to assess regional deterrence. I hope to test out the following three hypotheses:

To test these three hypotheses, I establish a correlation between our time series. $x_{t}$ is the time series representing CT Operation and $v$ is representative of the attacks within 19 months. This thesis has categorised the data within months as there are too few per weeks to regroup it in this way. Furthermore, monthly evolution can model clearly deterrence due to the significant events for both 


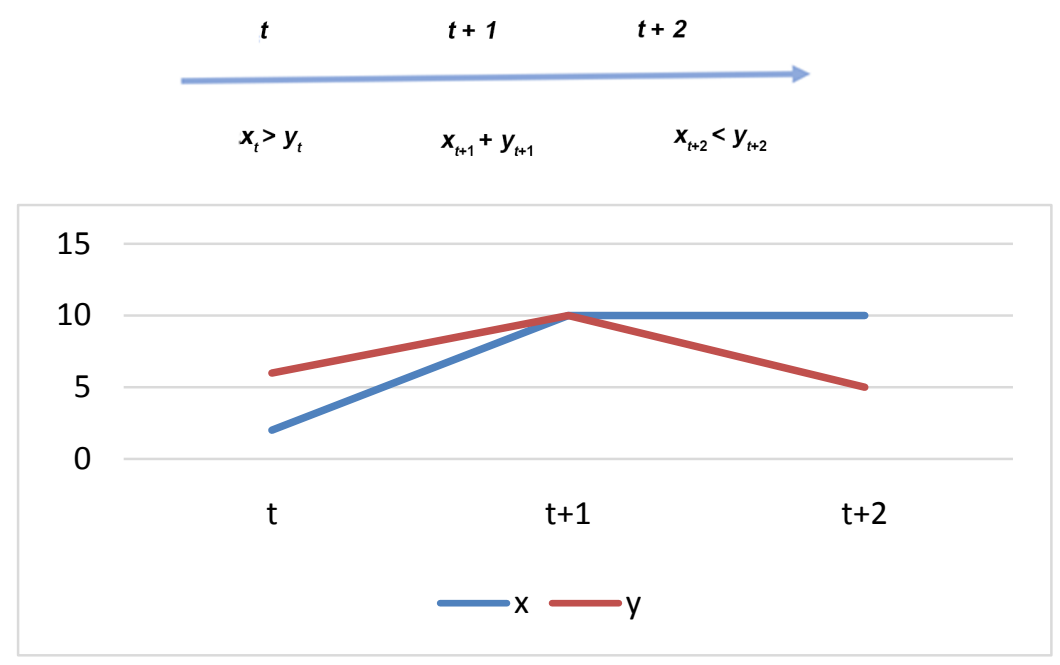

Figure 8. Perfect deterrence model.

time series. The first step to our analysis is to model the events in a comprehensive graph based on their numbers.

Our first observation is the significant difference between the number of attacks and the number of CT operations which therefore suggests that a lack of guardianship does equate to a high prevalence of attacks (Figure 9).

Running a Pearson Correlation test in SPSS indicates that there is no significant correlation between the two series. However, a Pearson test does not take in considering the value of time between both series which limits the cross-correlation. In order to establish a more accurate correlation, I ran both series in $R$. I aim to calculate the cross-variance between $x_{t}$ and $y_{t}$ where $x_{t}$ is delayed by $T$ samples. $\mu_{x}$ and $\mu_{y}$ I aim to obtain the cross-variance function $\sigma_{x y}(T)$ :

$$
\sigma_{x y}(T)=\frac{1}{N-1} \sum_{t=1}^{N}\left(x_{t-T}-\mu_{x}\right)\left(y_{t}-\mu_{y}\right)
$$

The cross-correlation coefficient is $r_{x}(T)$ that will be used to assess the strength of the correlations which is a normalised cross-variance that with a zero mean signal assumption.

$$
r_{x y}(T)=\frac{\sigma_{x y}(T)}{\sqrt{\sigma_{x x}(0) \sigma_{y y}(0)}}
$$

In $R$, the delay is measured through the lag function. This analytical function allows to count delays accessing prior rows at given physical offsets.

Disproving our previous observations, the cross-correlation function is 0.45 which indicates a small positive correlation between the two functions (Figure 10). The strongest correlation seen is in a period of four months. This means that the level of attacks appears to grow as the level of CT Operations grows with a high significance in a 4 months frame. These results thus appear to correlate with our second hypothesis but deny our third hypothesis meaning the deterrence model may not completely apply. 


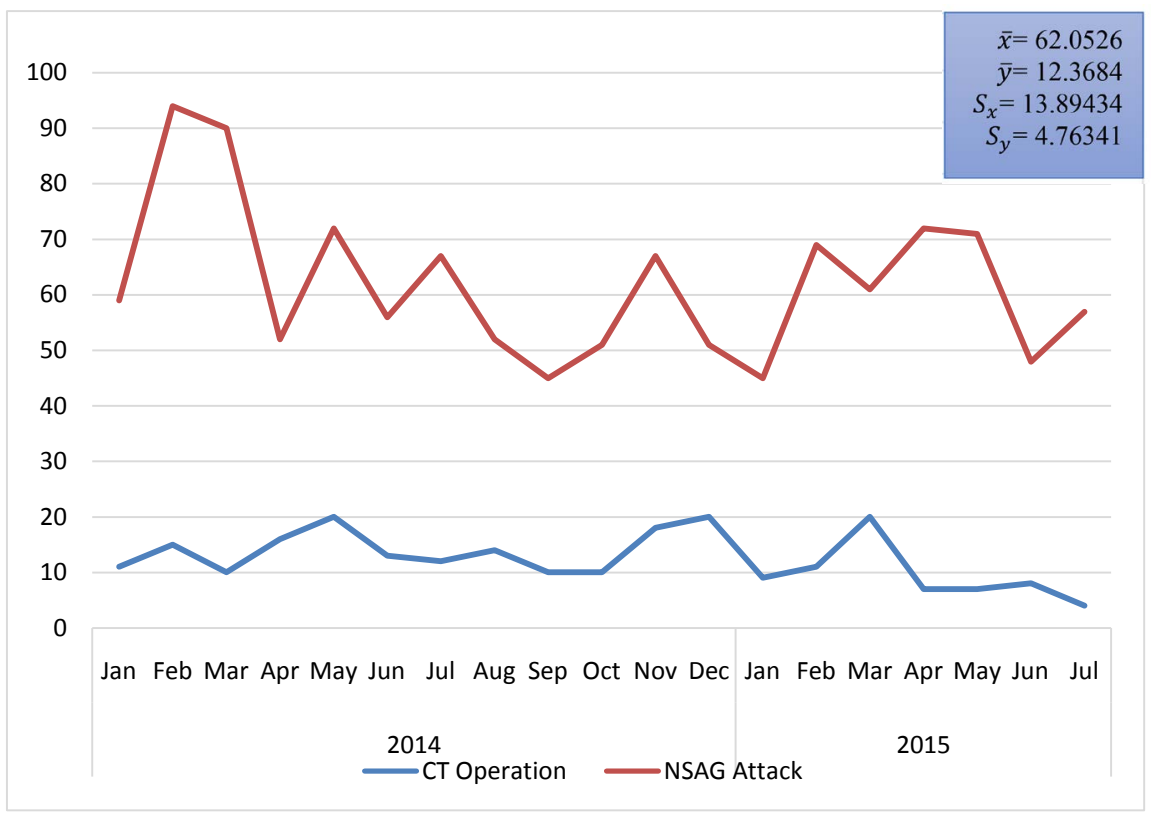

Figure 9. Evolutive comparison of the number of attacks and CT Operations.

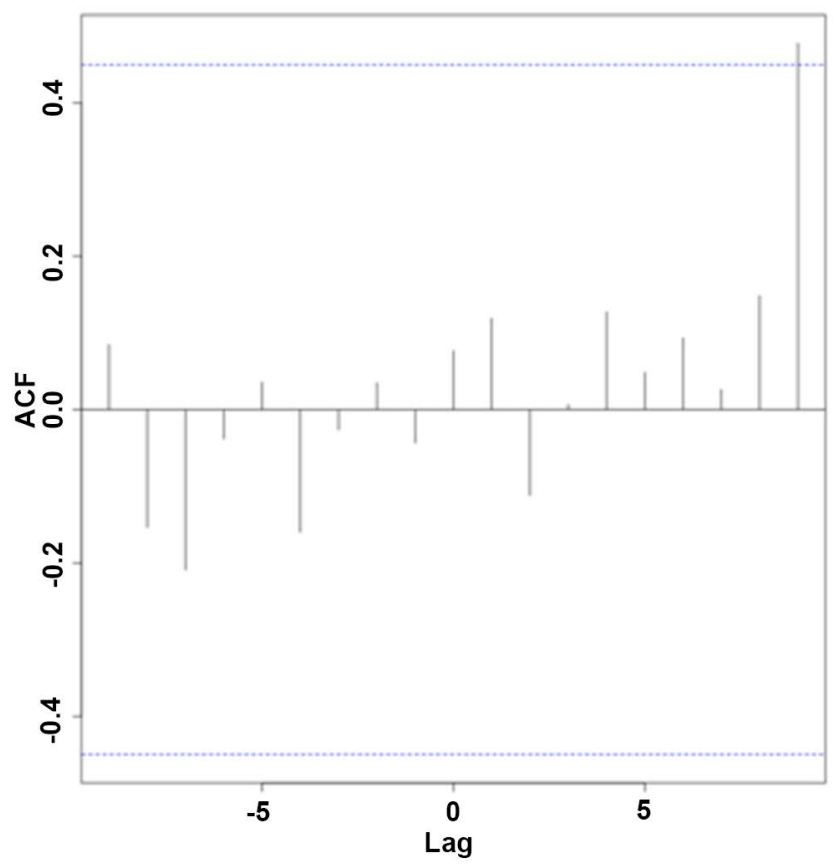

Figure 10. Correlation of the time series in $R$.

With the high differences between attacks and CT operations, it is difficult to really compare the general evolution of both events between January 2014 and July 2015. In order to better assess deterrence, modeling the two series at a similar scale is needed through z-scores previously explained in the previous section.

As indicated by the Cross-Correlation function, I can see the two time-series evolving in roughly the same way through our time frame (Figure 11). Two instances of deterrence are seen between September 2014 and March 2015. Indeed, 


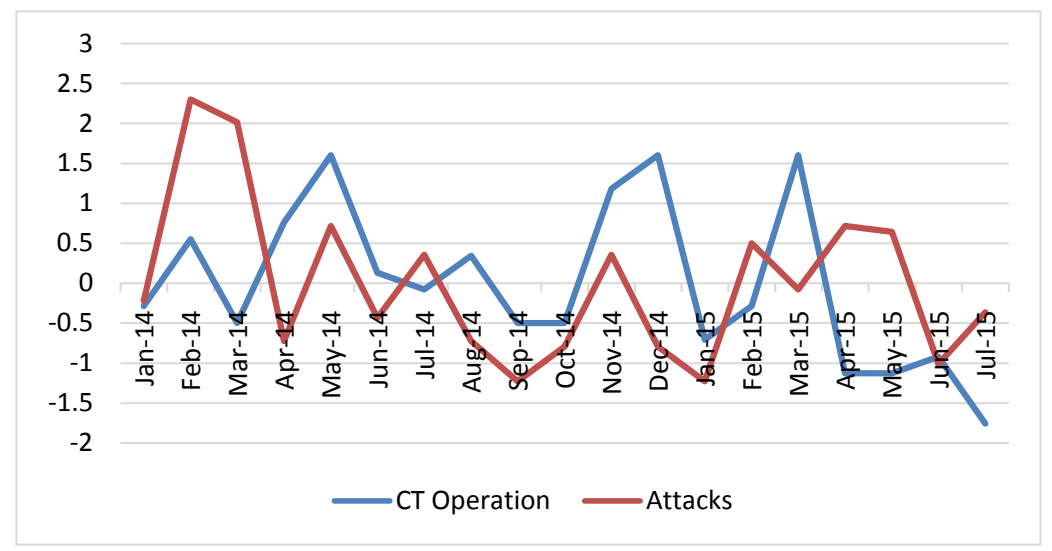

Figure 11. Comparative graphs modeled with Z-scores.

between September and October 2014, attacks grow as policing remains steady. Between October and mid-December 2015, policing grows and a noticeable decrease in attacks is seen starting mid-November. A drop in policing causes attacks to grow again in January 2015 to finally decrease mi-February due to a high growth in policing.

Are the evolutions similar in the two instances of deterrence? For the first instance of deterrence between September and mid-December 2014, attacks had a $49 \%$ increase for roughly a $100 \%$ increase in CT Operations. Furthermore, examining the second instance of deterrence between January 2015 to mid-March 2015, attacks had a 53\% increase for a $111 \%$ increase in CT Operations. The first drop in attacks is a $33 \%$ decrease and the second drop is only of $12 \%$. Therefore, I can conclude that there is an evolutive discrepancy between CT Operations and terrorist attacks. Indeed, in instances of deterrence, a 50\% evolution in attacks causes CT Operations to double. However, the drops in attacks are not as significant as initial attack growths. Furthermore, deterrence seems only to apply for periods of 2 months. Therefore, deterrence is not a process causing long-term change. This is perhaps due to the constant change of policing levels in the region. Perhaps steadier policing would allow for a more concrete deterrence process to take place. I can conclude overall that deterrence occurrences are not significant. Therefore, our second and third hypotheses are rejected.

\subsection{Political and Religious Deterrence}

Although our overall analysis seems to indicate more of a positive correlation rather than a negative one, I now aim to test deterrence for political and religious terrorism. For political terrorism, as it is country specific, I have picked the group with the highest number of terror occurrences. This is the Thai-Malay insurgencies in Thailand. I use z-scores once again to determine a comparative framework between CT Operations and Attacks.

From January 2014 to October 2014, it appears Hypothesis 1 related to Routine Activity Theory to be shown (Figure 12). Indeed, a lowering of policing indicates a rise in attacks. This relates back to Cohen and Felson's theory of the 


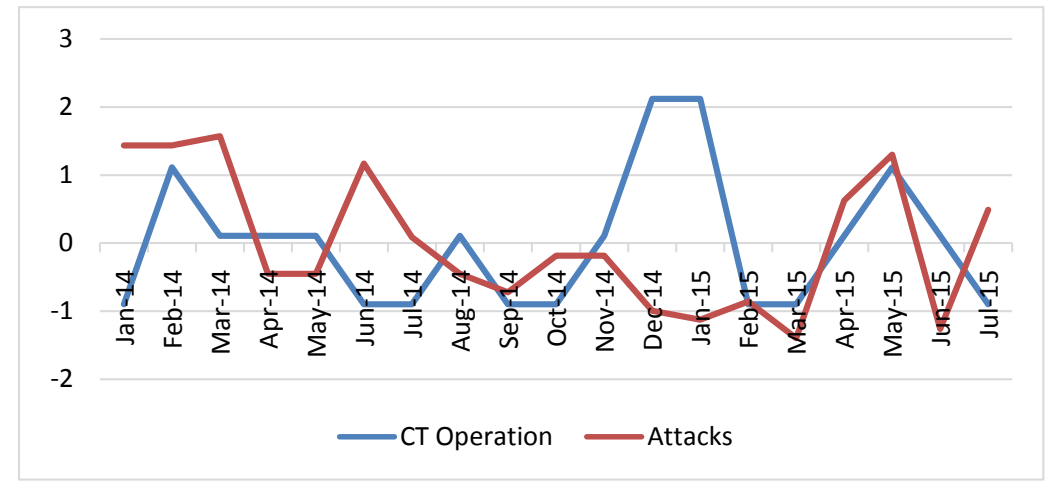

Figure 12. Thai-Malay insurgencies in Thailand.

absent guardian. Furthermore, for 311 attacks, only 17 attacks have been counted, thus roughly accounting for a 1/18 ratio. One clear occurrence of deterrence is seen between October 2014 and February 2015 where a huge peak of policing occurred. Indeed, policing tripled with attacks decreasing by $47 \%$. Once again, a deterrence occurrence is shown with a very high increase in policing that only correlates with about a half decrease of attacks. This would put into question the effectiveness of deterrence theory within the realm of counterterrorism.

I now aim to test deterrence theory within religious terrorism. All religious terrorism in the region relates to Extreme Islamism. Therefore, with this common aim, I have quantified all religious terror attacks and CT Operations in the region. Indeed, links have been proven between groups such as Abu Sayyaf and Jemaah Islamiyah. This does not mean however groups overlap in functions and activities, but simply that they share similar beliefs.

Once again, the tenant of Routine Theory seems to hold with one CT Operation corresponding to 6.6 attacks. Compared to our political study case, however, it seems that religious terrorism is much more policed. This may be explained by the media attention given to religious extremism. For instance, the United States has cooperated with Indonesia post-Bali bombings (Vaugh \& co, 2009) [27].

CT operations and Attacks appear positively correlated (Figure 13). Only one instance of moderate deterrence is seen from February 2015 to mid-March 2015. Policing tripled when attacks decreased by two. This is one of the closest negative correlation found so far in our data between the increase in policing and the following decrease in attacks. However, yet again deterrence appears more as a one-off occurrence rather than a general trend. Moreover, policing must increase significantly for attacks to drop. The correlation is not proportional.

Therefore, the data shows that deterrence theory is not completely applicable to our dataset, except for at a local level for political terrorism. CT Operations and Attacks appear moderately positively correlated in time with the highest significance seen in a period of 4 months. This could be explained by military clashes seen as common where military confrontation is heavily used as a 


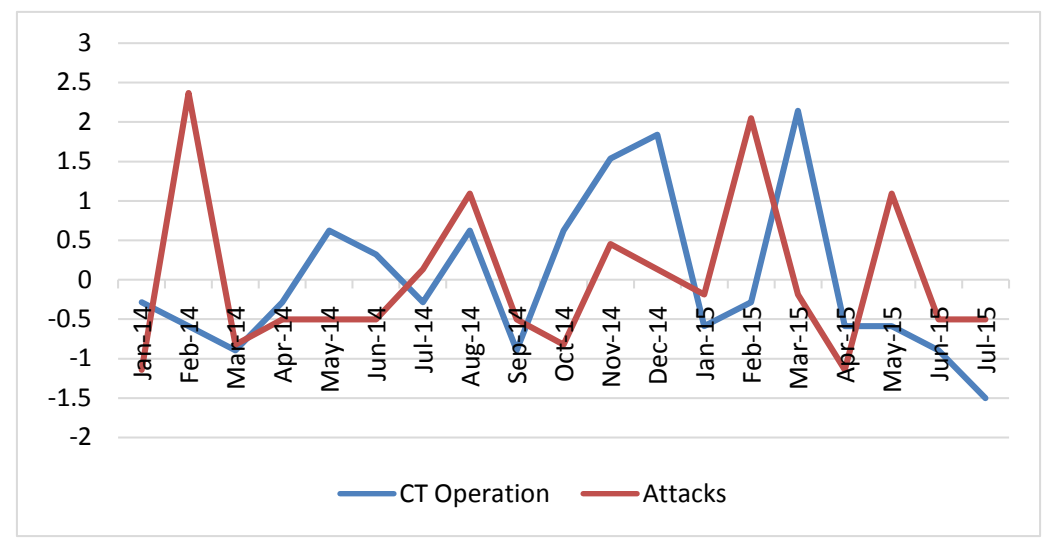

Figure 13. Evolution of religious terrorism in South East Asia.

counter-terror strategy. The huge discrepancy in frequencies of attacks and of CT Operations, however, limits our analysis as both datasets are not comparable in numbers. Perhaps an overall increase of CT Operations in the region would be beneficial to elaborating the model further.

\section{Conclusions}

Smith concludes that "terrorism is likely to remain persistent" in Southeast Asia but does not represent a major threat to the region (2010: p. 5) [28]. He further adds that the region has become better equipped at dealing with terrorism in the last decade. However, our dataset suggests that improvements could be made in counter-terror strategies especially in Myanmar, Thailand and the Philippines with a much higher frequency of attacks observed compared to CT Operations undertaken.

This study has provided a reconceptualization of terrorism. With the prevalence of political terrorism in the region, patterns are discernible. Indeed, military clashes are at the forefront of counter-terrorism with confrontational militarized occurrences putting into question Ganor's clear distinction of terrorism from guerrilla warfare (2002) [20]. Although civilians remain important casualties, soldiers are heavily targeted, even by Islamic religious organizations such as ASG. Moreover, terror organizations in Southeast Asia being militarized factions deviate from the image of the decentralized sub-state Islamic organizations. Therefore, this study provides a more accurate assessment of terrorism which is invaluable to counter-terror strategies and aims to break from religious essentialist frameworks.

Routine Activity Theory is, therefore, a valuable insight into terrorism as figures of the motivated offender, the capable guardian and the suitable target emerge. A routine in targeting is seen with a data skewed towards military clashes. Furthermore, the hypothesis of contagion theory is accepted within localized contexts where similar groups are involved. Finally, no generalized patterns of deterrence were detected within our data but counter-terrorist operations do correlate positively with attacks due to the direct confrontational aspect of military 
clashes. Deterrence is more effective within political terrorism where the highest deterrence occurrences were recorded. However, the discrepancy between attacks and CT Operations limits deterrence testing as it lacks proportionality.

Smith states that a deeper evaluation of terrorism in Southeast Asia requires more attention to transnational linkages (2010: p. 5). There is indeed a growing connectivity between the local and global. Further research into criminal network theory would allow for a better understanding of contagion, deterrence, and targeting. I see this study as a starting point to empirical research within terror studies and hope for further analysis to provide a deeper look into the inner structures of terrorism. Indeed, the identification of terror patterns as seen above will provide invaluable help to organizations such as Interpol to prevent and reduce terror violence.

\section{Acknowledgements}

I would like to present my deepest thanks to my supervisor Dr. Paolo Campana for his invaluable guidance throughout the year. I am thankful for his advice and his constant smiles, despite the numerous hours spent in his office trying to work out mathematical modelling for this thesis. I would like to thank the Department of Criminology in Cambridge, especially the Director of our program Dr. Kyle Treiber, for her insightful teaching throughout the year. I would also like to thank my parents for their support and encouragements of my academic endeavors.

\section{References}

[1] Duyvesteyn, I. (2004) How New Is the New Terrorism? Studies in Conflict \& Terrorism, 27, 439-454. https://doi.org/10.1080/10576100490483750

[2] Cymer, J.A. (2003) America's Culture of Terrorism. University of North Carolina Press.

[3] Lafree, G., Morris, N. and Dugan, L. (2010) Cross-National Patterns of Terrorism: Comparing Trajectories for Total, Attributed and Fatal Attacks 1970-2006. British Journal of Criminology, 50, 622-649. https://doi.org/10.1093/bjc/azp066

[4] Cohen, L.R. and Felson, M. (1979) Social Change and Crime Rate Trends: A Routine Activity Approach. American Sociological Review, 44, 588-608. https://doi.org/10.2307/2094589

[5] Chamard, S. (2010) Routine Activities. In: McLaughlin, E. and Newburn, T., Eds., Criminological Theory, Sage Publications, London. https://doi.org/10.4135/9781446200926.n12

[6] Dugan, L., Lafree, G. and Piquero, A.R. (2005) Testing a Rational Choice Model of Airline Hijackings. Criminology, 43, 1031-1066. https://doi.org/10.1111/j.1745-9125.2005.00032.x

[7] Hawley, A. (1950) Human Ecology: A Theory of Community Structure. Ronald, New York.

[8] Crawford, A. and Evans, K. (2012) Crime Prevention and Community Safety. In: Maguire, M., Morgan, R. and Reiner, R., Eds., The Oxford Handbook of Criminology, 5th Edition, Oxford University Press, Oxford.

https://doi.org/10.1093/he/9780199590278.003.0026 
[9] Sherman, L.W., Gartin, P.P. and Buerger, M.E. (1989) Hot Spots of Predatory Crime: Routine Activities and the Criminology of Place. Criminology, 27, 27-55. https://doi.org/10.1111/j.1745-9125.1989.tb00862.x

[10] Osgood, D.W. and Anderson, A.L. (2004) Unstructured Socializing and Rates of Delinquency. Criminology, 42, 519-550. https://doi.org/10.1111/j.1745-9125.2004.tb00528.x

[11] Eck, J.E. and Weisburd, D. (1995) Crime Places in Crime Theory. In: Eck, J.E. and Weisburd, D., Eds., Crime and Place, Crime Prevention Studies, Vol. 4, Willow Tree Press.

[12] Weenink, A. (2015) Behavioural Problems and Disorders among Radicals in Police Files. Perspectives on Terrorism, 9, 17-33.

[13] Interpol Analytical Report (2014) Fusion Taskforce Project Pacific: Emerging Terrorism Trends and Threats in the Southeast Asia Region.

[14] Hamilton-Hart, N. (2005) Terrorism in Southeast Asia: Expert Analysis, Myopia and Fantasy. Pacific Review, 18, 303-325.

[15] Smith, P.J. (2010) Terrorism in Southeast Asia: A Strategic Assessment. In: Montesano, M.J. and PohOnn, L., Eds., Regional Outlook. Southeast Asia 2010-2011, Institute of Southeast Asian Studies, Singapore.

[16] Cheong, P.H. and Lundry, C. (2012) Presumption, Transmediation and Resistance: Terrorism and Man-Hunting in Southeast Asia. American Behavioral Scientist, 56, 488-510. https://doi.org/10.1177/0002764211429365

[17] Hodges, A. (2011) The "War on Terror" Narrative: Discourse and Intersexuality in the Construction and Contestation of Sociopolitical Reality. Oxford University Press, Oxford. https://doi.org/10.1093/acprof:oso/9780199759590.001.0001

[18] Hesch and Pedahzur (2004).

[19] Atran, S. (2003) Genesis of Suicide Terrorism. Science, 299, 1534-1539. https://doi.org/10.1126/science.1078854

[20] Ganor, B. (2002) Defining Terrorism: Is One Man's Terrorist Another Man's Freedom Fighter. Police Practice and Research, 3, 287-304. https://doi.org/10.1080/1561426022000032060

[21] Jackson, R. (2009) The Study of Terrorism after 11 September 2011: Problems, Challenges, and Future Developments. Political Science Review, 7, 171-184.

[22] Held, V. (2004) Terrorism and War. The Journal of Ethics, 8, 59-75. https://doi.org/10.1023/B:JOET.0000012252.68332.ff

[23] Almog, D. (2004) Cumulative Deterrence and the War on Terrorism. Parameters, 34,4 .

[24] Frey, B.S. and Luechinger, S. (2003) How to Fight Terrorism: Alternatives to Deterrence. Defence and Peace Economics, 14, 237-249. https://doi.org/10.1080/1024269032000052923

[25] Reynald, D.M. (2011) Guarding against Crime. Ashgate Publishing Limited.

[26] Trager, R.F. and Zagorcheva, D.P. (2005) Deterring Terrorism. International Security, 30, 87-123.

[27] Vaugh, B., Chanlett-Avery, E., Dolven, B., Manyin, M.E., Martin, M.F. and Niksch, L.A. (2009) Terrorism in Southeast Asia. Congressional Research Service.

[28] Smith, M. (2007) Ethnic Conflicts in Burma: From Separatism to Federalism. In: Tan, A.T.H., Ed., A Handbook of Terrorism and Insurgency in Southeast Asia, Edward Elgar Publishing Limited. https://doi.org/10.4337/9781847207180.00025 